Revista Tecné, Episteme y Didaxis: TED. Año 2014, Número Extraordinario. ISSN Impreso: 0121-3814, ISSN web: 2323-0126

Memorias, Sexto Congreso Internacional sobre Formación de Profesores de Ciencias. 08 al 10 de octubre de 2014, Bogotá

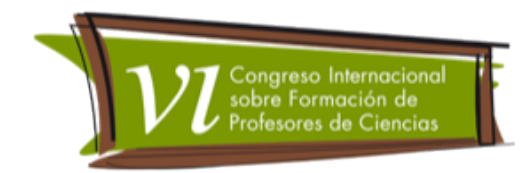

\title{
Habilidades cognitivolingüísticas para describir, explicar, justificar y argumentar en estudiantes de Tecnología en Gestión de la Producción Agroindustrial
}

Castelblanco Castro, Jenny Lucíal; Córdoba Martínez, Fanny² y García Martínez, Álvaro 3

Categoría 2. Trabajo de investigación

\section{Resumen}

En la siguiente ponencia se presentan una parte de los resultados obtenidos y analizados en el marco de una investigación llevada a cabo con un grupo de estudiantes de la Tecnología en Gestión de la Producción Agroindustrial de la Universidad Tecnológica de Bolívar-Edupol, bajo una modalidad de educación virtual a distancia, en relación a sus habilidades cognitivolingüísticas para describir, explicar, justificar y argumentar, durante la aplicación de una estrategia didáctica dentro de una asignatura denominada Procesos Industriales.

De modo que el texto aborda de manera sintética: objetivo de la investigación, fundamento teórico asumido, metodología construida y aplicada, resultados y conclusiones, específicamente para la categoría señalada.

\section{Palabras clave}

Habilidades cognitivolingüísticas, describir, explicar, justificar, argumentar.

\section{Objetivos}

La investigación objeto de divulgación en esta ponencia, se trazó como objetivo principal: Reconocer y analizar las habilidades cognitivolingüísticas para describir, explicar, justificar y argumentar en las producciones comunicativas de los estudiantes pertenecientes al programa de Tecnología en Gestión de la

\footnotetext{
1 Universidad Distrital Francisco José de Caldas, Universidad Tecnológica de Bolívar-Edupol. jcastelblanco@udistrital.edu.co

2 Universidad Distrital Francisco José de Caldas. fannycordoba_29@yahoo.es

3 Universidad Distrital Francisco José de Caldas. alvaro.garcia@udistrital.edu.co
} 
Revista Tecné, Episteme y Didaxis: TED. Año 2014, Número Extraordinario. ISSN Impreso: 0121-3814, ISSN web: 2323-0126

Memorias, Sexto Congreso Internacional sobre Formación de Profesores de Ciencias. 08 al 10 de octubre de 2014, Bogotá

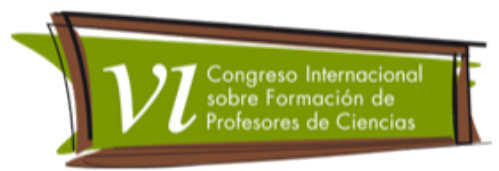

Producción Agroindustrial de la UTB en alianza con Edupol durante la aplicación de una estrategia didáctica en el módulo de Procesos Industriales.

\section{Marco teórico}

En esta investigación se asumieron como fundamento teórico la perspectiva de Jorba, Gómez \& Prat (2000) sobre habilidades cognitivolingüísticas, enfatizada en la producción de textos escritos desde diversas áreas curriculares y en la tipología textual o la estructura del texto.

A continuación se presenta las concepciones asumidas para cada habilidad cognitivolingüística analizada:

Tabla 1. Fundamentación teórica y construcción de la definición de la habilidad cognitivolingüística de describir. Adaptado de Jorba et al. (2000, pág. 34).

\begin{tabular}{|l|l|}
\hline \multicolumn{2}{|c|}{ Habilidad cognitivolingüística: Describir } \\
\hline $\begin{array}{l}\text { Autores en los cuales se basaron Jorba, } \\
\text { Gómez y Prat }\end{array}$ & $\begin{array}{l}\text { Definición propuesta por Jorba, Gómez y } \\
\text { Prat }\end{array}$ \\
\hline J. Veslin & $\begin{array}{l}\text { Producir proposiciones o enunciados que } \\
\text { enumeren cualidades, propiedades, } \\
\text { características, acciones, etc., mediante todo } \\
\text { tipo de códigos y lenguajes verbales y no } \\
\text { verbales, de objetos, hechos, fenómenos, } \\
\text { acontecimientos, etc., sin establecer relaciones } \\
\text { causales al menos explícitamente. }\end{array}$ \\
\hline
\end{tabular}

Tabla 2. Fundamentación teórica y construcción de la definición de la habilidad cognitivolingüística de explicar. Adaptado de Jorba et al. (2000, pág. 37).

\begin{tabular}{|l|l|}
\hline \multicolumn{3}{|c|}{ Habilidad cognitivolingüística: Explicar } \\
\hline $\begin{array}{l}\text { Autores en los cuales se basaron Jorba, } \\
\text { Gómez y Prat }\end{array}$ & Definición propuesta por Jorba, Gómez y Prat \\
\hline J. Veslin & $\begin{array}{l}\text { Presentar razonamientos o argumentos } \\
\text { estableciendo relaciones (deben haber relaciones } \\
\text { causales explícitamente) en el marco de las } \\
\text { cuales los hechos, acontecimientos o cuestiones } \\
\text { explicadas adquieren sentido y llevan a } \\
\text { comprender o a modificar un estado de } \\
\text { conocimiento. }\end{array}$ \\
R. Duval &
\end{tabular}


Revista Tecné, Episteme y Didaxis: TED. Año 2014, Número Extraordinario. ISSN Impreso: 0121-3814, ISSN web: 2323-0126

Memorias, Sexto Congreso Internacional sobre Formación de Profesores de Ciencias. 08 al 10 de octubre de 2014, Bogotá

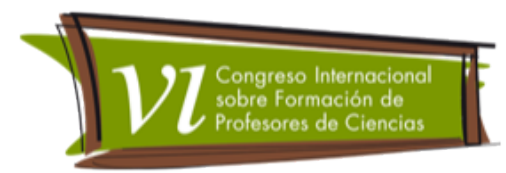

Tabla 3. Fundamentación teórica y construcción de la definición de la habilidad cognitivolingüística de justificar. Adaptado de Jorba et al. (2000, pág. 39).

\begin{tabular}{|l|l|}
\hline \multicolumn{2}{|c|}{ Habilidad cognitivolingüística: Justificar } \\
\hline $\begin{array}{l}\text { Autores en los cuales se basaron Jorba, } \\
\text { Gómez y Prat }\end{array}$ & $\begin{array}{l}\text { Definición propuesta por Jorba, Gómez y } \\
\text { Prat }\end{array}$ \\
\hline C. G. Debanc, P. Bange, J. B. Grize, R. Duval, & $\begin{array}{l}\text { Producir razones o argumentos, establecer } \\
\text { relaciones entre ellos y examinar su } \\
\text { aceptabilidad con el fin de modificar el valor } \\
\text { epistémico de la tesis en relación con el } \\
\text { corpus de conocimientos en que se incluyen } \\
\text { los contenidos objeto de la tesis. }\end{array}$ \\
\hline
\end{tabular}

Tabla 4. Fundamentación teórica y construcción de la definición de la habilidad cognitivolingüística de argumentar. Adaptado de Jorba et al. (2000, pág. 40).

\begin{tabular}{|l|l|}
\hline \multicolumn{2}{|c|}{ Habilidad cognitivolingüística: Argumentar } \\
\hline $\begin{array}{l}\text { Autores en los cuales se basaron Jorba, Gómez } \\
\text { y Prat }\end{array}$ & $\begin{array}{l}\text { Definición propuesta por Jorba, } \\
\text { Gómez y Prat }\end{array}$ \\
\hline C. G.-Debanc, R. Duval, M. Charoles, J. M. Adam, & $\begin{array}{l}\text { Producir razones o argumentos, } \\
\text { establecer relaciones entre ellos y } \\
\text { examinar su aceptabilidad con el fin de } \\
\text { modificar el valor epistémico de la tesis } \\
\text { desde el punto de vista del destinatario. }\end{array}$ \\
\hline
\end{tabular}

\section{Metodología}

Esta investigación se enmarcó en el enfoque cualitativo (Vasilachis, 2006, p. 26), de tipo descriptivo-explicativo (Hernández, Fernández, \& Baptista, 1997) y se realizó mediante una ruta metodológica deductiva flexible que evolucionó dentro de una dinámica heurística y que permitió el descubrimiento y el hallazgo, más que hacer comprobaciones o verificaciones en los resultados y las conclusiones.

La población analizada, según los aportes de Stake (citado en Rodríguez \& Valldeoriola, 2009, pág. 58), correspondió a 5 estudiantes en ciclo tecnológico (de 32 en total) pertenecientes al programa en Gestión de la Producción Agroindustrial, en el marco de la UTB en alianza con Edupol, en modalidad virtual a distancia y en metodología por convergencia de medios.

La muestra fue intencionada, siendo los criterios para su delimitación: diversidad y heterogeneidad geográfica, número de productos comunicativos publicados, género mixto, edades entre los 20 y 60 años, de quinto semestre y matriculados en 
Revista Tecné, Episteme y Didaxis: TED. Año 2014, Número Extraordinario. ISSN Impreso: 0121-3814, ISSN web: 2323-0126

Memorias, Sexto Congreso Internacional sobre Formación de Profesores de Ciencias. 08 al 10 de octubre de 2014, Bogotá

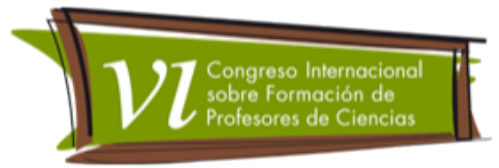

el módulo de Procesos Industriales, durante el segundo período académico del año 2013.

A continuación se presenta el diagrama de fases de la investigación respecto a la categoría de habilidades cognitivolingüísticas:

Figura 1. Diagrama metodológico

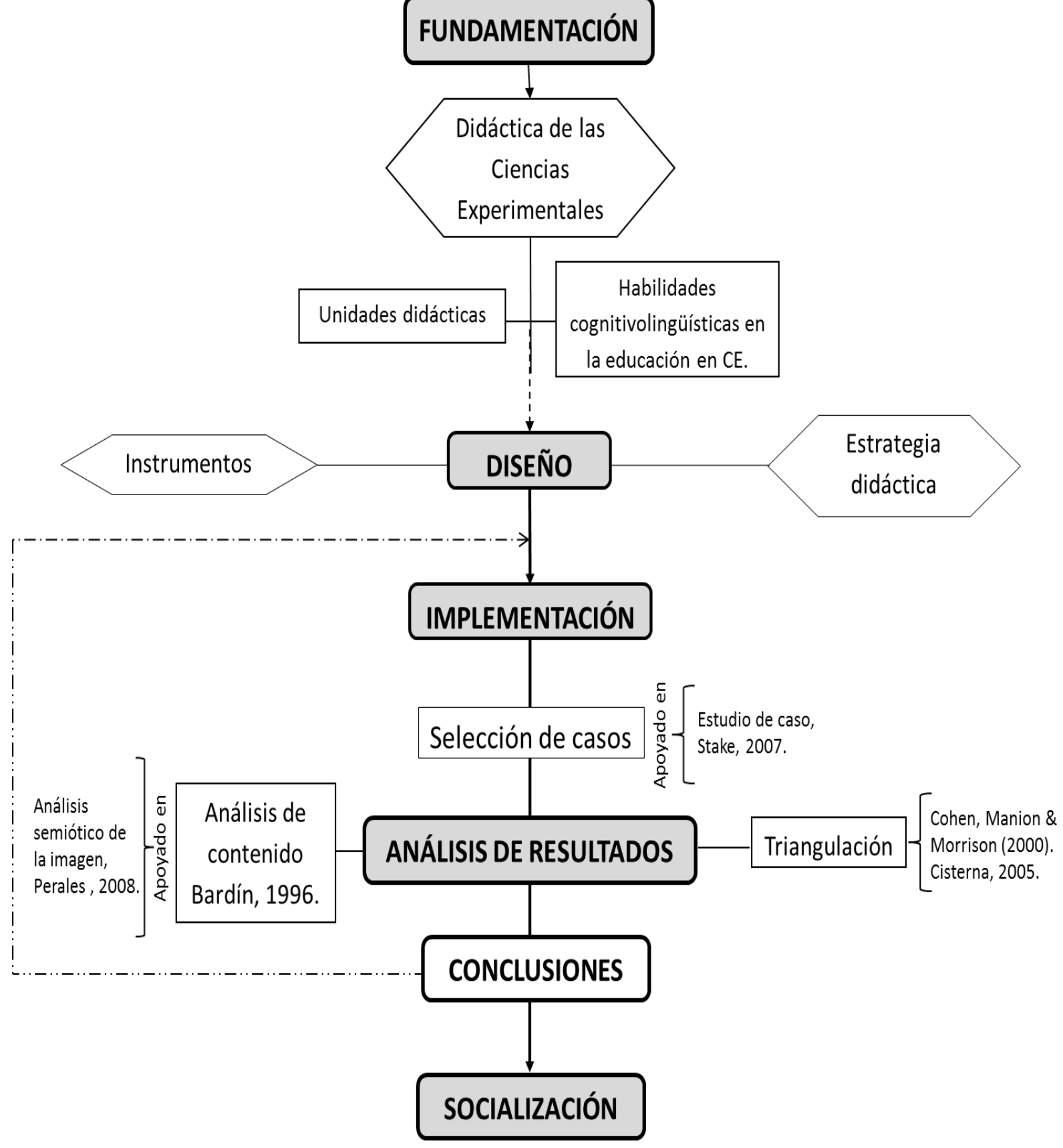


Revista Tecné, Episteme y Didaxis: TED. Año 2014, Número Extraordinario. ISSN Impreso: 0121-3814, ISSN web: 2323-0126

Memorias, Sexto Congreso Internacional sobre Formación de Profesores de Ciencias. 08 al 10 de octubre de 2014, Bogotá

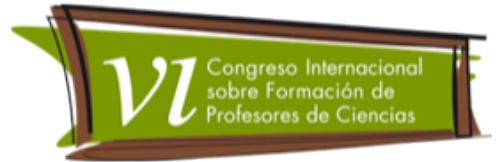

\section{Resultados}

En la investigación desarrollada se analizaron un total de 59 productos comunicativos que fueron elaborados por los estudiantes de la muestra seleccionada y que se publicaron durante las teleclases en el foro sincrónico o en Aula Virtual de Aprendizaje en el foro asincrónico.

En el gráfico 1, se resumen el total de productos comunicativos recopilados y analizados.

Gráfico 1. Porcentaje de los productos comunicativos objeto de análisis que fueron publicados por los cinco estudiantes.

\section{PRODUCTOS COMUNICATIVOS PUBLICADOS Y ANALIZADOS}

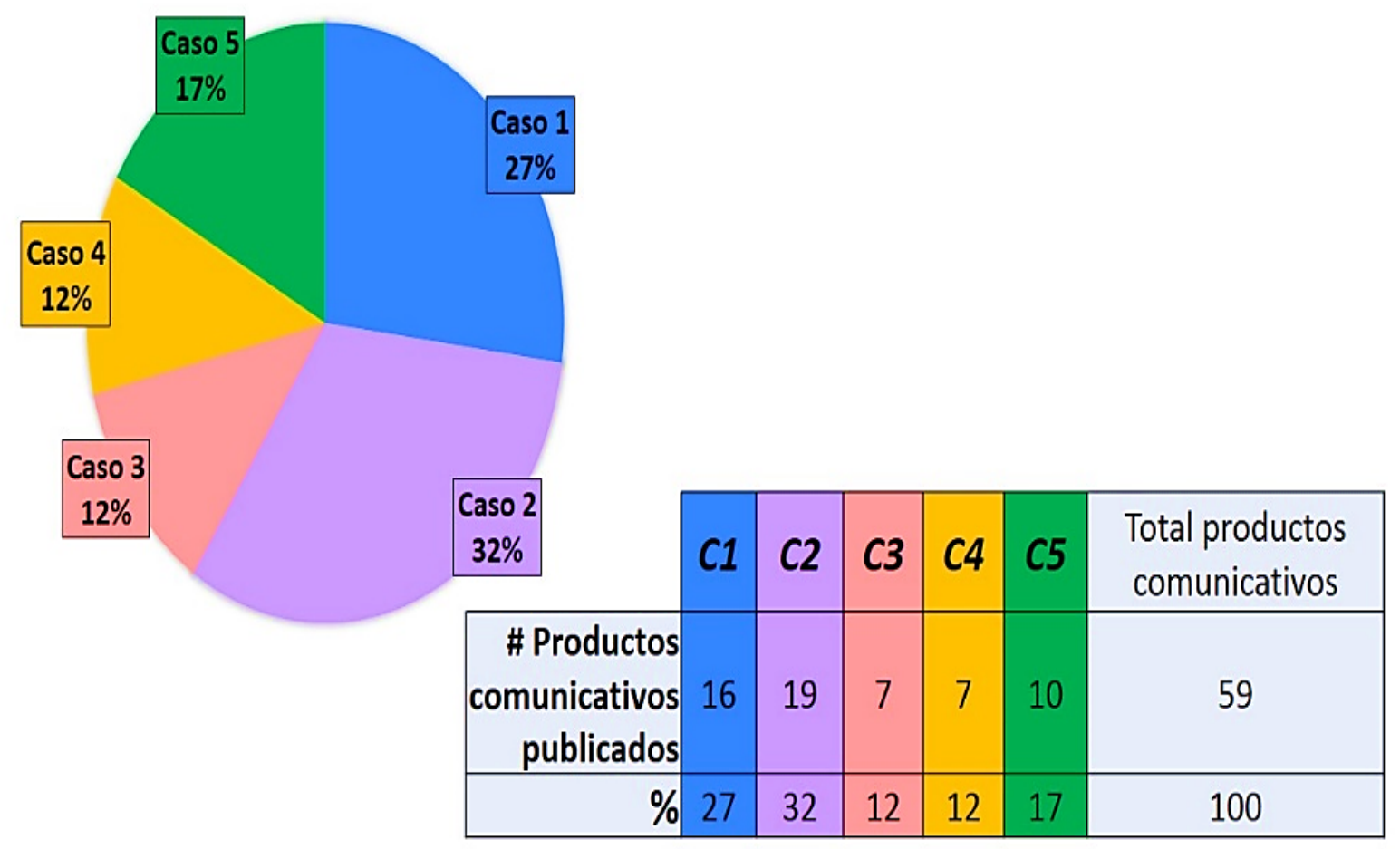

Ahora bien, cada producto comunicativo recopilado, fueron analizados a la luz de los elementos que se muestran en la tabla 1 y empleando el análisis documental propuesto por Bardín (1996). 
Revista Tecné, Episteme y Didaxis: TED. Año 2014, Número Extraordinario. ISSN Impreso: 0121-3814, ISSN web: 2323-0126 Memorias, Sexto Congreso Internacional sobre Formación de Profesores de Ciencias. 08 al 10 de octubre de 2014, Bogotá

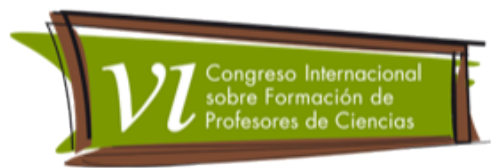

Tabla 5. Subcategorías e indicadores aplicados al análisis de los productos comunicativos de los 5 estudiantes, en relación de la categoría de habilidades cognitivolingüísticas.

\begin{tabular}{|c|c|c|}
\hline CATEGORÍA & $\begin{array}{c}\text { Subcafegoría o } \\
\text { unidades de } \\
\text { sentido }\end{array}$ & Indicadores \\
\hline \multirow{5}{*}{$\begin{array}{l}\text { HABILIDADES } \\
\text { COGNITIVO } \\
\text { UNGUÍSTICAS } \\
\text { (Describir, } \\
\text { explicar, } \\
\text { justificary } \\
\text { argumentar) }\end{array}$} & Opiniones & $\begin{array}{l}\text { El estudiante elabora un producto comunicativo que } \\
\text { propone únicamente afirmaciones o aseveraciones } \\
\text { desde el sentido común y/o el conocimiento } \\
\text { científico-escolar, en relación a los contenidos } \\
\text { conceptuales, metodológicos y/o actitudinales } \\
\text { propios del módulo de Procesos industriales. }\end{array}$ \\
\hline & Descripciones & $\begin{array}{l}\text { El estudiante publica un producto comunicativo que } \\
\text { se estructura en proposiciones que buscan detallar o } \\
\text { caracterizar una situación, objeto o fenómeno en el } \\
\text { contexto de los contenidos conceptuales, } \\
\text { metodológicos y/o actitudinales propios del módulo } \\
\text { de Procesos industriales. }\end{array}$ \\
\hline & Explicaciones & $\begin{array}{l}\text { El estudiante construye un producto comunicativo en } \\
\text { el cual: } \\
\text { 1. Se explicitan razones y se establecen relaciones } \\
\text { entre ellas (causa - efecto). } \\
\text { 2. Las mismas son evidencia de modificación del } \\
\text { estodo de conocimiento en relación al corpus } \\
\text { teórico de procesos agroindustriales }\end{array}$ \\
\hline & Justificaciones & $\begin{array}{l}\text { E estudiante construye un producto comunicativo en } \\
\text { el cual: } \\
\text { 1. Se explicitan razones y se establecen relaciones } \\
\text { entre ellas (causa - efecto). } \\
\text { 2. Las mismas son evidencia de modificación del } \\
\text { estodo de conocimiento en relación al corpus } \\
\text { teórico de procesos agroindustriales } \\
\text { 3. Las razones son aceptables dentro del corpus de } \\
\text { conocimiento de procesos industriales }\end{array}$ \\
\hline & Argumentaciones & $\begin{array}{l}\text { El estudiante construye un producto comunicativo en } \\
\text { el cual: } \\
\text { 1. Se explicitan razones y se establecen relaciones } \\
\text { entre ellas (causa - efecto). } \\
\text { 2. Las mismas son evidencia de modificación del } \\
\text { estodo de conocimiento en relación al corpus } \\
\text { teórico de procesos agroindustriales } \\
\text { 3. Las razones son aceptables dentro del corpus de } \\
\text { conocimiento de procesos industriales } \\
\text { 4. Las razones tienen la intención de modificar el } \\
\text { estodo de conocimiento del destinatario en relación } \\
\text { al corpus sobre procesos agroindustriales. }\end{array}$ \\
\hline
\end{tabular}


Revista Tecné, Episteme y Didaxis: TED. Año 2014, Número Extraordinario. ISSN Impreso: 0121-3814, ISSN web: 2323-0126

Memorias, Sexto Congreso Internacional sobre Formación de Profesores de Ciencias. 08 al 10 de octubre de 2014, Bogotá

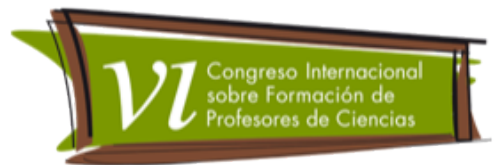

En la siguiente gráfica, se observan las habilidades detectadas por estudiante en cada producto comunicativo publicado:

Gráfico 2. Uso de las habilidades cognitivolingüísticas por producto comunicativo en el Caso 1.

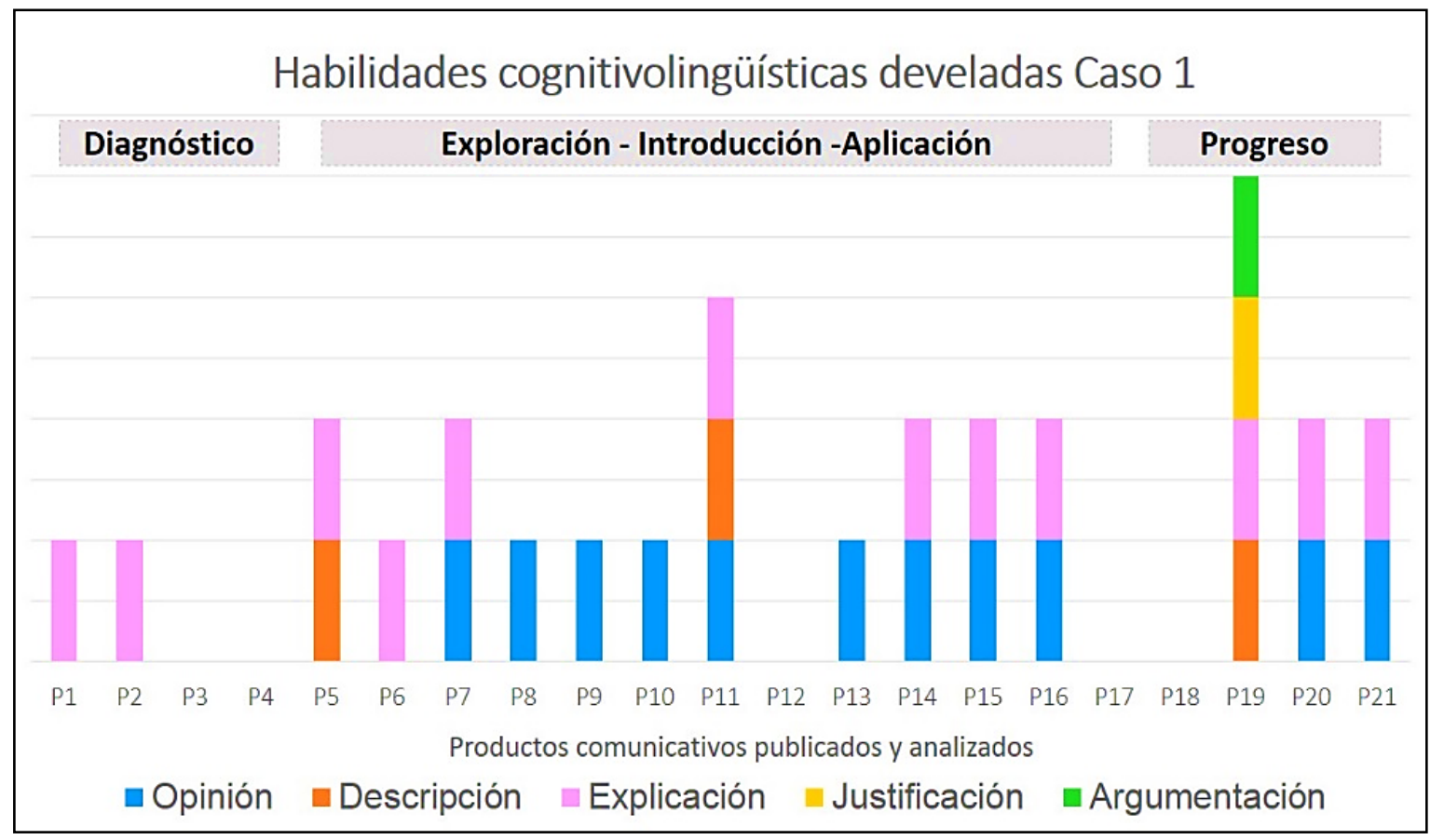

El caso 1 se trata de un estudiante en el que se logró apreciar que hacía procesos de autorregulación y metacognición dado el nivel de productos que publicó sin que la mayoría de ellos constituyera factor de calificación definitiva. Se observó que cuando el estudiante presentaba confusiones-en especial con el concepto de cambios de la materia-tendía a casi no usar sus habilidades cognitivolingüísticas y se limitaba a opinar, ya fuera sustentándose en conocimientos cotidianos o científico-escolares no válidos dentro del corpus de conocimientos de procesos industriales. No obstante, cuando el estudiante superó sus vacíos conceptuales, se atrevió a usar sus habilidades cognitivolingüísticas, en especial, la explicación en 12 producciones comunicativas. La habilidad cognitivolingüística de la descripción sólo es usada 4 veces por el estudiante, pero de forma muy básica y fundamentada por conocimientos cotidianos. Sólo en 1 producción el estudiante usó todas las habilidades cognitivolingüísticas, fundamentándose tanto en conocimientos cotidianos como científico-escolares válidos y con la intencionalidad comunicativa de convencer. 
Revista Tecné, Episteme y Didaxis: TED. Año 2014, Número Extraordinario. ISSN Impreso: 0121-3814, ISSN web: 2323-0126

Memorias, Sexto Congreso Internacional sobre Formación de Profesores de Ciencias. 08 al 10 de octubre de 2014, Bogotá
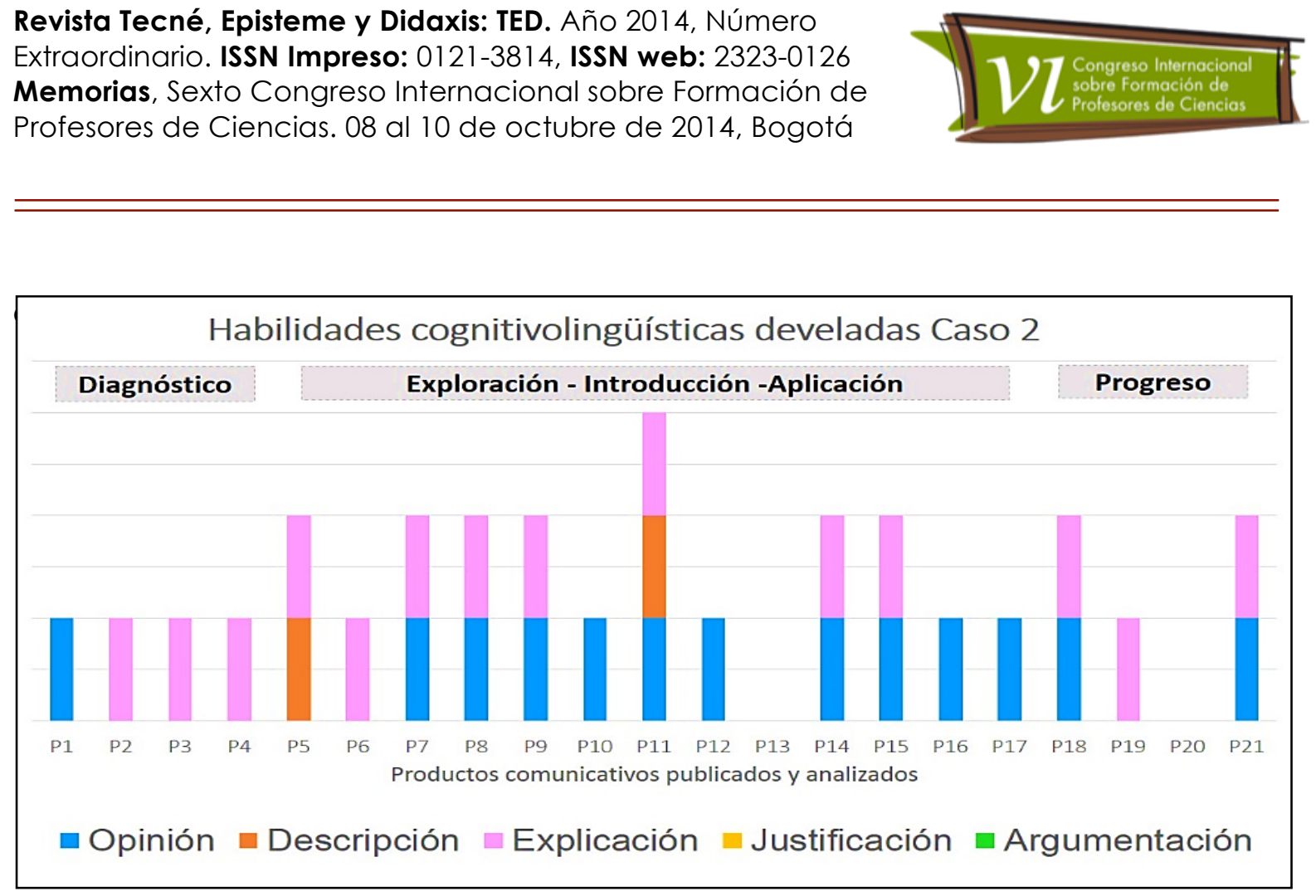

El caso 2 se trata de la estudiante que más producciones comunicativas publicó, lo que demostró interés en su proceso académico. Sin embargo, de las 19 producciones comunicativas que publicó, en 9 tenía serios problemas de comprensión tanto del concepto de cambios de la materia como de balance de materia. Con lo cual se concluye que, el publicar demasiadas actividades no significa que las mismas presenten una calidad y estén acordes con lo aceptado dentro del corpus de conocimientos de productos industriales.

En el desarrollo de la estrategia didáctica la estudiante manifestó serios problemas de entendimiento tanto del concepto de cambios de la materia como de balance de materia. De lo anterior se deriva el hecho de que en el análisis de sus producciones comunicativas se encuentre tanta dispersión en relación al tipo de conocimientos en los que se fundamenta y los niveles de complejidad a los que acude. La explicación es la habilidad cognitivolingüística que más usa la estudiante-lo hace en 13 producciones-y sólo en 3 producciones se valió de la descripción. Es preciso aclarar que, tanto sus descripciones como sus explicaciones son muy precarias y tienden a estar acompañadas de opiniones. 
Revista Tecné, Episteme y Didaxis: TED. Año 2014, Número Extraordinario. ISSN Impreso: 0121-3814, ISSN web: 2323-0126

Memorias, Sexto Congreso Internacional sobre Formación de Profesores de Ciencias. 08 al 10 de octubre de 2014, Bogotá

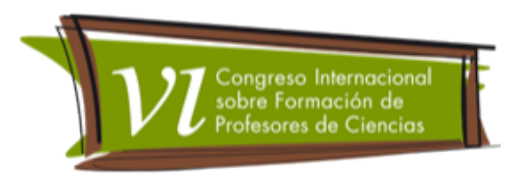

Gráfico 4. Uso de las habilidades cognitivolingüísticas por producto comunicativo en el Caso 3.

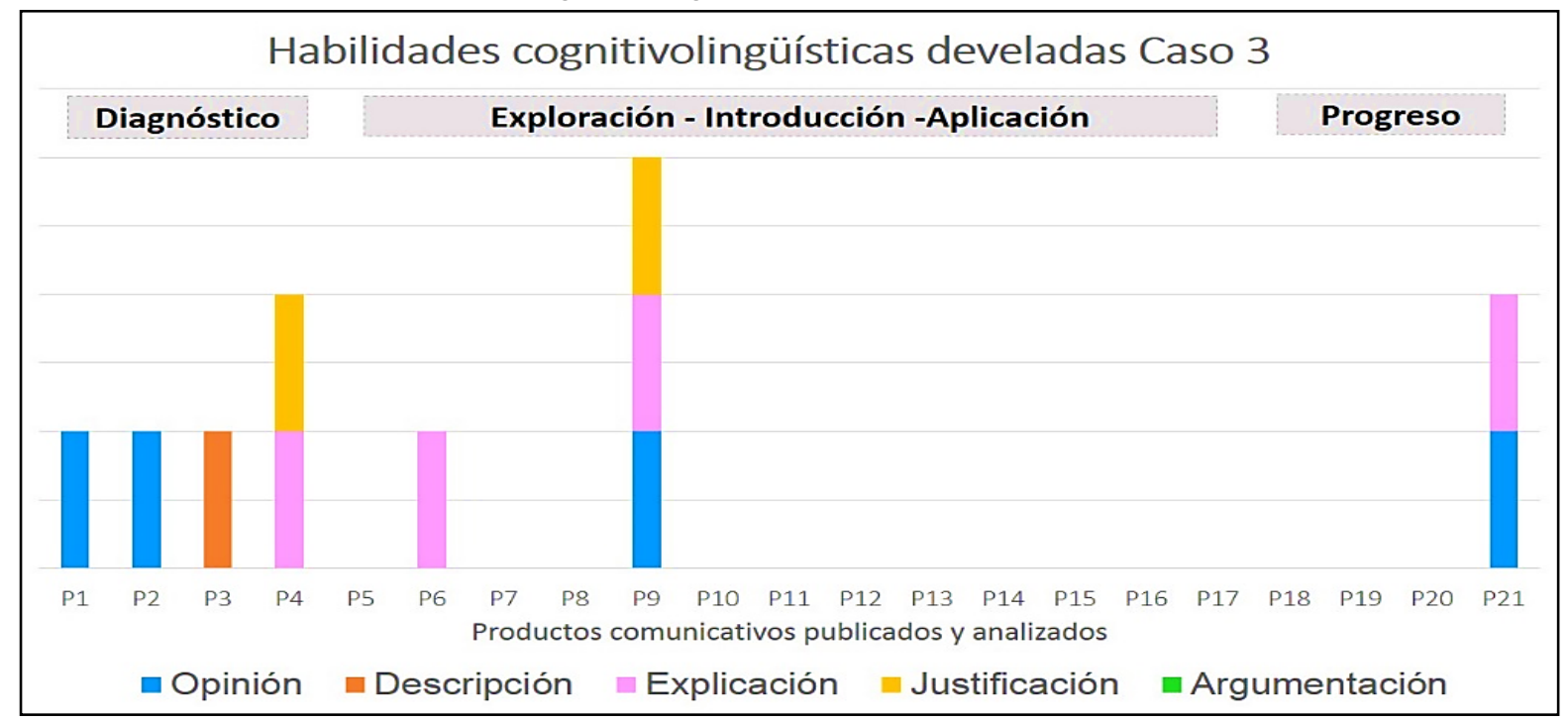

La estudiante del Caso 3 sólo publicó 7 productos comunicativos, sin embargo, en la mayoría de ellos, demostró comprensión de los conceptos. Es decir, aunque publicó pocas actividades, las pocas que publicó eran correctas de acuerdo al corpus de conocimiento de procesos industriales. La estudiante se vale en mayor porcentaje de la habilidad cognitivolingüística de la explicación-en 3 productos comunicativos-. La justificación sólo la usa en 2 producciones y la descripción en 1. En 2 actividades no usa las habilidades cognitivolingüísticas sino que sólo opina. En general, el uso que le da la estudiante a sus las habilidades cognitivolingüísticas es muy básico. Las opiniones acompañan en 2 actividades a las habilidades cognitivolingüísticas.

Gráfico 5. Uso de las habilidades cognitivolingüísticas por producto comunicativo en el Caso 4.

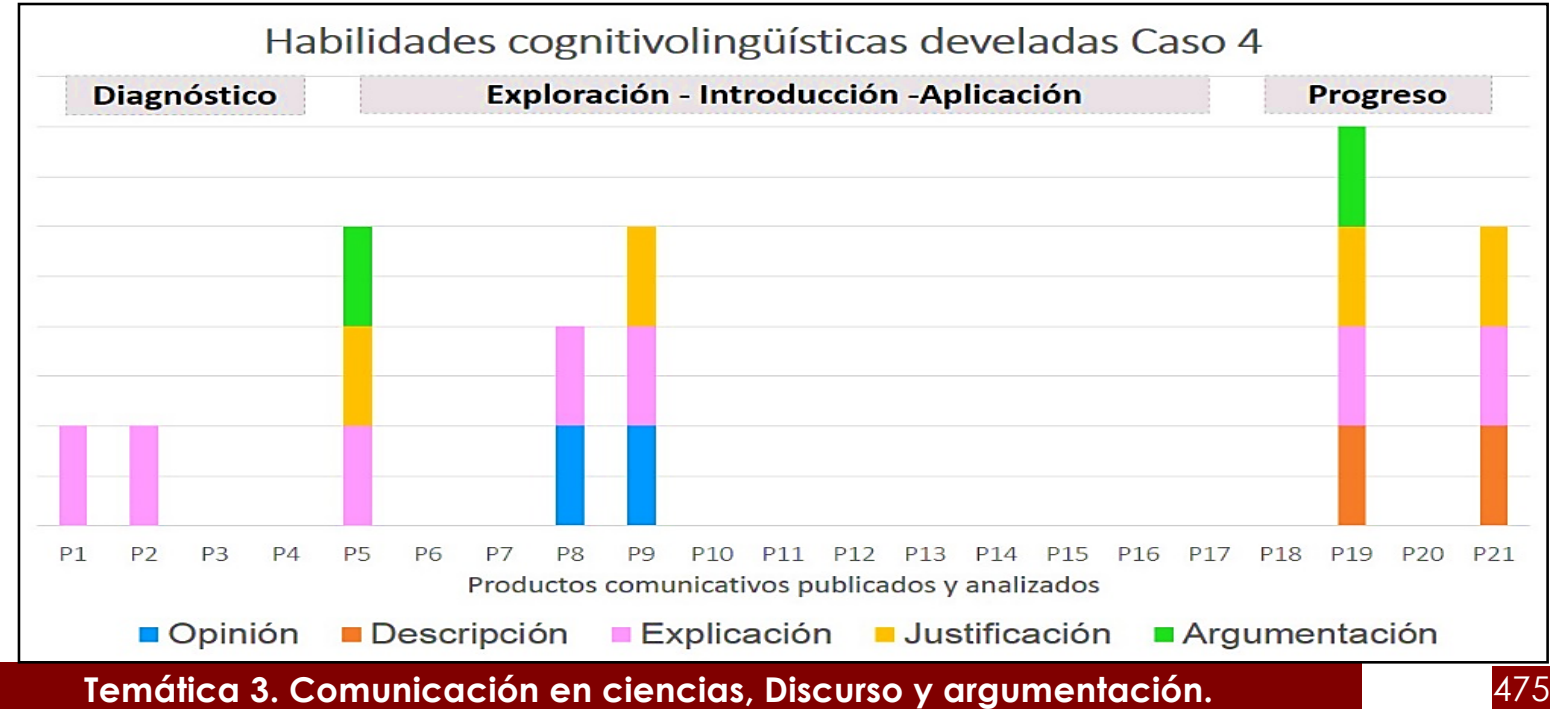


Revista Tecné, Episteme y Didaxis: TED. Año 2014, Número Extraordinario. ISSN Impreso: 0121-3814, ISSN web: 2323-0126

Memorias, Sexto Congreso Internacional sobre Formación de Profesores de Ciencias. 08 al 10 de octubre de 2014, Bogotá

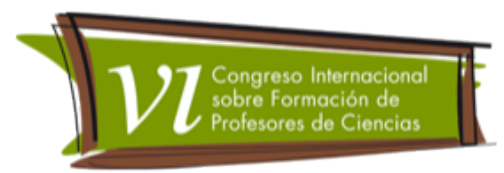

A pesar de que el estudiante del Caso 4 sólo publicó 7 actividades de las 21 propuestas en la estrategia didáctica, las mismas presentaban una calidad adecuada y manifestaban el uso de las habilidades cognitivolingüísticas. En todas sus actividades el estudiante usó la habilidad cognitivolingüística de la explicación-sola en 2 oportunidades y acompañada de otras habilidades cognitivolingüísticas en 5 actividades-. Hace uso de la justificación en 4 productos comunicativos y de los 2 productos comunicativos, aunque de forma básica. Es interesante ver cómo las opiniones en este caso sólo son usadas en dos productos comunicativos para acompañar a las habilidades cognitivolingüísticas.

Gráfico 6. Uso de las habilidades cognitivolingüísticas por producto comunicativo en el Caso 5.

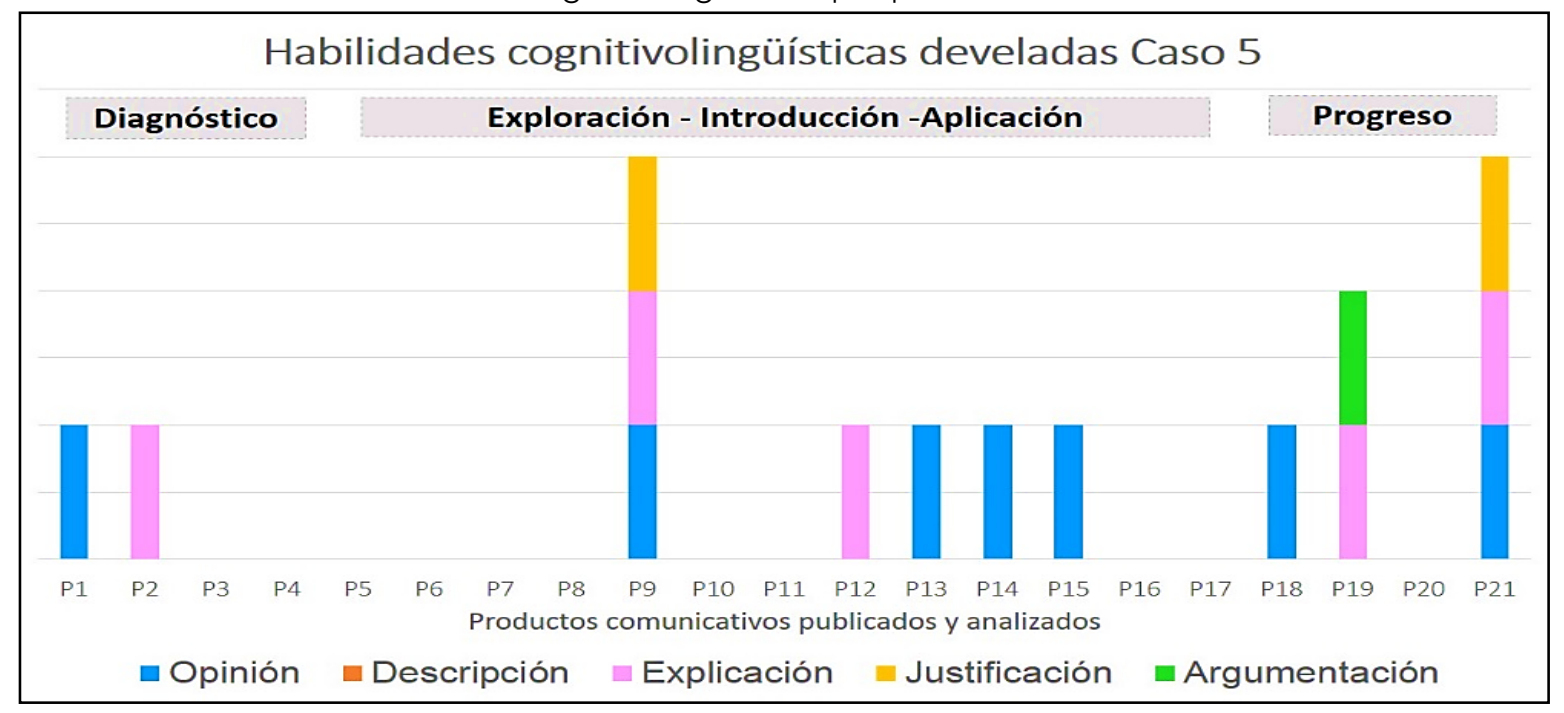

El estudiante del Caso 5 sólo presentó la mitad de los productos comunicativos propuestos en la estrategia didáctica. La habilidad cognitivolingüística que más usa es la explicación-lo hace en 4 producciones-le sigue la justificación-en dos producciones-y la argumentación sólo la usa en 1 producción con la intencionalidad comunicativa de convencer. En las producciones en que el estudiante desarrolla sus habilidades cognitivolingüísticas manifiesta comprensión de los conceptos trabajados. En las producciones en las que el estudiante recurre a la opinión se evidencia dificultades de comprensión de los conceptos.

\section{Conclusiones}

En los análisis se evidenció que la explicación es la habilidad cognitivolingüística a la que más apelan los estudiantes. De 59 producciones comunicativas analizadas, se encontró que más del $70 \%$ (42 productos comunicativos) estaban 
Revista Tecné, Episteme y Didaxis: TED. Año 2014, Número Extraordinario. ISSN Impreso: 0121-3814, ISSN web: 2323-0126

Memorias, Sexto Congreso Internacional sobre Formación de Profesores de Ciencias. 08 al 10 de octubre de 2014, Bogotá

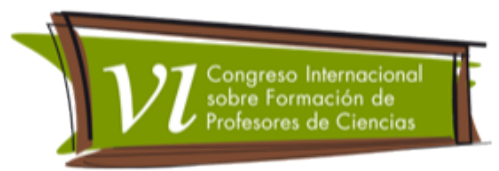

estructuradas en razones explícitas que pretendían establecer relaciones de causa-efecto y, las mismas, constituían evidencia de modificación del estado de conocimiento de los sujetos respecto al corpus teórico de procesos industriales. El segundo lugar no lo ocupa una habilidad cognitivolingüística propiamente dicha sino las opiniones como expresiones comunicativas configuradas a partir de afirmaciones o aseveraciones provenientes, en su mayoría, del sentido común o los conocimientos cotidianos de los estudiantes, desprovistas de razones que las sustentaran. Esto se evidenció en el 63\% (37) de producciones comunicativas.

La justificación ocupa el tercer lugar con el 15\% (9 producciones) de aparición en la comunicación escrita de los estudiantes. Se observó que en este tipo de producciones, los estudiantes acudían a la construcción explícita de razones que buscaban responder al porqué de un fenómeno relacionado con los procesos industriales. Estas justificaciones, además de ser evidencia de la modificación del estado de conocimiento de los estudiantes, eran aceptadas dentro del corpus de conocimientos de procesos industriales. Con tan sólo el $1 \%$ de diferente entre la justificación y la descripción, esta última ocupa el cuarto lugar en un 14\% (8) del total de las producciones analizadas. Los estudiantes que emplearon esta habilidad, demostraron incluir en su producto comunicativo proposiciones que buscaban detallar o caracterizar una situación, objeto o fenómeno en el contexto de los procesos agroindustriales.

Respecto a la habilidad cognitivolingüística más compleja, es decir, la argumentación ocupa el quinto lugar con el 7\% (4 productos) de aparición en las producciones publicadas por los estudiantes. Tal vez, las apariciones esporádicas de esta habilidad en las comunicaciones de los estudiantes, se explique porque implica, además de los elementos ya mencionados para la justificación, que las razones que se emitan tengan la intencionalidad de modificar el estado de conocimiento del destinatario, en otras palabras convencer al interlocutor.

Se logró apreciar que cuando los estudiantes opinan, acuden a conocimientos cotidianos, pero normalmente, no son válidos dentro del corpus de conocimiento de procesos industriales, lo cual evidencia confusión a nivel conceptual en relación a los cambios en la materia y balance de materia. Cuando los estudiantes presentaban este tipo de dificultades conceptuales, la protagonista en sus productos comunicativos era la opinión, la cual acompañaba a las habilidades cognitivolingüísticas-excepto a la argumentación-. No obstante, cuando los estudiantes superaban estas dificultades, eran las habilidades cognitivolingüísticas de la descripción, la explicación y/o la justificación las que 
Revista Tecné, Episteme y Didaxis: TED. Año 2014, Número Extraordinario. ISSN Impreso: 0121-3814, ISSN web: 2323-0126

Memorias, Sexto Congreso Internacional sobre Formación de Profesores de Ciencias. 08 al 10 de octubre de 2014, Bogotá

ganaban protagonismo sobre la opinión, soportadas, principalmente, en conocimientos científico-escolares válidos en la mayoría de las producciones con estas condiciones.

Las producciones comunicativas asociadas a las actividades de la estrategia didáctica de naturaleza asincrónica y multimodal-icónica y escrita-develaron mayor calidad de las habilidades cognitivolingüísticas de los estudiantes, puesto que demandaban relacionar el texto escrito con la imagen en el marco de una situación problémica en el área de procesos industriales. Por lo tanto, se infiere que los estudiantes ante actividades complejas y estructuradas a partir de diversos lenguajes, hacen gala de sus conocimientos y aprendizajes, empleando habilidades cognitivolingüísticas que superan los niveles de explicación.

A través de estrategias didácticas que propongan a los estudiantes hacer manifiestas sus habilidades cognitivolingüísticas para describir, explicar, justificar y argumentar, es posible detectar falencias, obstáculos y avances a nivel conceptual, metodológico, actitudinal y, por supuesto, comunicativo de conceptos estructurantes para la comprensión de las ciencias, tales como el cambio químico y la cuantificación de relaciones-balance de materia en el contexto de los productos agroindustriales-, en la medida en que el lenguaje materializa los procesos mentales que llevan a cabo los estudiantes.

Finalmente, entre las estrategias lingüísticas que utilizaron los estudiantes para desarrollar o no sus habilidades cognitivolingüísticas se encuentran por un lado, la transpolación de la oralidad a la escritura, es decir, escribir lo que se deseaban decir. Lo cual conllevó que en algunos enunciados se adoptaran la informalidad y la espontaneidad como características propias de la oralidad y no la decantación del léxico o el uso correcto de las convenciones de la escritura. Por el otro lado, la incorporación en el lenguaje de normas de convivencia social como la cortesía como un afán de proyectar una imagen positiva en búsqueda de la aprobación de las docentes, pero no de los compañeros (as).

\section{Referencias bibliográficas}

Bardín, L. (1996). Análisis de contenido. (C. Suárez, Trad.). Madrid: Akal.

Cisterna, F. (2005). Categorización y triangulación como procesos de validación del conocimiento en investigación cualitativa. Theoria, 14 (1), 61-71. 
Revista Tecné, Episteme y Didaxis: TED. Año 2014, Número Extraordinario. ISSN Impreso: 0121-3814, ISSN web: 2323-0126

Memorias, Sexto Congreso Internacional sobre Formación de Profesores de Ciencias. 08 al 10 de octubre de 2014, Bogotá

Cohen, L., Manion, L., \& Morrison, K. (2000). Research Methods in Education. Recuperado de http://www.stibamalang.ac.id/uploadbank/pustaka/RM/RESEARCH\%20METHOD\%20COHEN\% 20ok.pdf

Hernández, R., Fernández, C., \& Baptista, P. (1997). Metodología de la investigación. Recuperado de http://www.upsin.edu.mx/mec/digital/metod_invest.pdfJorba, J., Gómez, I., \&

Jorba, J., Gómez, I., \& Prat, À. (Ed.). (2000). Hablar y escribir para aprender: Uso de la lengua en situación de enseñanza-aprendizaje desde las áreas curriculares. Madrid: Síntesis/ICE de la UAB.

Perales, J. (2008). La imagen en la enseñanza de las ciencias: Algunos resultados de investigación en la Universidad de Granada, España. Recuperado de http://www.scielo.cl/pdf/formuniv/v1n4/art03.pdf

Rodríguez, D., \& Valldeoriola, J. (2009). Metodología de la investigación. Barcelona: UOC.

Stake, R. (2007). Investigación con estudio de casos. (R. Filella, Trad.) Madrid: Morata.

Vasilachis, I. (2006). Estrategias de investigación cualitativa. Barcelona: Gedisa Editorial. 